\title{
Monitoring the Interaction of Two Heterocyclic Compounds on Carbon Steel by Electrochemical Polarization, Noise, and Quantum Chemical Studies
}

\author{
Vinod P. Raphael, ${ }^{1}$ Shaju K. Shanmughan, ${ }^{1}$ and Joby Thomas Kakkassery ${ }^{2}$ \\ ${ }^{1}$ Department of Chemistry, Government Engineering College, Thrissur, Kerala 680009, India \\ ${ }^{2}$ Research Division, Department of Chemistry, St. Thomas' College (Autonomous), Thrissur, Kerala 680001, India \\ Correspondence should be addressed to Shaju K. Shanmughan; shaju5699@gmail.com
}

Received 30 August 2016; Revised 24 October 2016; Accepted 3 November 2016

Academic Editor: Flavio Deflorian

Copyright ( 2016 Vinod P. Raphael et al. This is an open access article distributed under the Creative Commons Attribution License, which permits unrestricted use, distribution, and reproduction in any medium, provided the original work is properly cited.

\begin{abstract}
A heterocyclic phenylhydrazone 2-[(E)-(2-phenylhydrazinylidene)methyl]pyridine (P2APH) and its reduced form 2-[(2phenylhydrazinyl)methyl]pyridine (RP2APH) were synthesized, characterized, and subjected to corrosion inhibition investigation on carbon steel (CS) in $1 \mathrm{M} \mathrm{HCl}$ using gravimetric, polarization, electrochemical noise, quantum chemical, and surface studies. P2APH showed more inhibition capacity than RP2PPH. But RP2PPH was very stable in acid medium and showed pronounced corrosion inhibition efficacy for days. Energy of HOMO and LUMO, their difference, number of electrons transferred, electronegativity, chemical hardness, and so forth were evaluated by quantum chemical studies. Agreeable correlation was observed between the results of quantum chemical calculations and other corrosion monitoring techniques.
\end{abstract}

\section{Introduction}

Acid corrosion is a serious problem in many metal industries. Metal surface cleaning processes like pickling and descaling will escalate the rate of corrosion appreciably since these practices consume large amount of acids. In oil industry, acidizing of oil wells with strong acids enhances the rate of corrosion of oil pipes. Generally $\mathrm{HCl}$ or $\mathrm{H}_{2} \mathrm{SO}_{4}$ is used for the above industrial purposes. The only solution to combat corrosion in these circumstances is the application of corrosion inhibitors [16]. Investigation of corrosion inhibition response of various molecules is very much alive in contemporary research. Many organic molecules possessing aromatic rings and heterocyclic atoms act as corrosion inhibitors in acidic media [7-10]. Structure and geometry of a molecule have a definite role in preventing the corrosion of metal in acid medium. Sometimes inhibitor molecules react with the aggressive medium and this leads to alteration in the inhibition response. For instance, the corrosion inhibition behaviour of Schiff base $N, N^{\prime}$-bis(salicylidene)-1,2-ethylenediamine (Salen), mixture of its parent compounds, and reduced form of Salen on carbon steel in $1 \mathrm{M} \mathrm{HCl}$ solution was studied by da Silva et al. [11] using corrosion potential measurements, polarization studies, EIS, and spectrophotometric measurements. Results obtained in the presence of Salen were similar to those obtained in the presence of the parent mixture, implying that in acid medium the Salen molecule undergoes hydrolysis, regenerating its precursor molecules. Reduced Salen exhibited more inhibition efficiency than Salen.

To explore the mechanism of corrosion inhibition, contemporary investigators rely on computational quantum chemical and molecular simulation techniques [1218]. Industries are ever in search of soluble, highly stable, economical, and potential corrosion inhibitors. In the present course of study, we synthesized two highly water soluble heterocyclic compounds derived from pyridine-2-aldehyde. This article reveals the corrosion inhibition behaviour of two heterocyclic molecules on carbon steel in $\mathrm{HCl}$ medium, which was explored by gravimetric, electrochemical, quantum chemical, and surface analytical techniques. 


\section{Materials and Method}

2.1. Synthesis and Characterization. The phenylhydrazone (P2APH) was synthesized by the condensation of equimolar mixtures of pyridine-2-aldehyde and phenylhydrazine hydrochloride in ethanol medium under reflux condition for $4 \mathrm{~h}$. The mixture was cooled in ice and the precipitated pale yellow coloured solid was filtered, washed with ethanol-water (1:1) mixture, and dried [19].

$5 \mathrm{mmol}$ of P2APH was dissolved in ethanol-water mixture $(1: 1)$. The mixture was cooled in ice bath and ethanolic solution of $\mathrm{NaBH}_{4}(1 \mathrm{~g}$ in $10 \mathrm{~mL})$ was added dropwise with constant stirring until the yellow colour of the reaction mixture disappeared. This mixture was kept for $10 \mathrm{~h}$ and the precipitated product (RP2APH) was filtered, washed with small quantities of water-ethanol mixture $(1: 1)$, and dried [20].

The products were characterized by elemental (Vario EL III Element Analyzer) analysis analysis and mass (Shimadzu, QP 2010 GCMS), nmr (Bruker Avance III HD, dmso-d solvent), and IR (Shimadzu Affinity-1, KBr pellet method) spectroscopic analyses.

2.2. Metal Specimen and Corrosive Medium. Carbon steel coupons were abraded $(1 \times 1 \times 0.15 \mathrm{~cm})$ with various grades of $\mathrm{SiC}$ papers $(120,400,600,800,1000$, and 1200$)$, washed with soap solution, and degreased by acetone. The approx. composition of the steel specimen was determined by EDAX technique $(0.58 \% \mathrm{C}, 0.07 \% \mathrm{Mn}, 0.02 \% \mathrm{P}, 0.015 \% \mathrm{~S}, 0.02 \%$ $\mathrm{Si}$, and Fe the rest, Hitachi SU6600 model SEM). A stock solution of P2APH and RP2APH $(1.0 \mathrm{mM})$ in $1 \mathrm{M} \mathrm{HCl}$ was prepared and diluted with $1 \mathrm{M} \mathrm{HCl}$ solution to get aggressive solutions in different concentrations $(0.2-1.0 \mathrm{mM})$.

2.3. Gravimetric Studies. The metal specimens were immersed in the aggressive medium for 4 days at $29 \pm 0.2^{\circ} \mathrm{C}$ with periodical evaluation of the corrosion rate. The rate of corrosion $[21,22]$ was determined by

$$
v=\frac{K W}{D S t}
$$

where $v=$ corrosion rate $\left(\mathrm{mmy}^{-1}\right), W=$ weight loss $(\mathrm{g}), S=$ surface area of metal specimen $\left(\mathrm{cm}^{2}\right), t=$ time of treatment (h), $D=$ density of specimen $\left(\mathrm{gcm}^{-3}\right)$, and $K=$ a constant $\left(8.76 \times 10^{4}\right)$.

The inhibition efficiency $\left(\eta_{w} \%\right)$ was obtained [21] by the following equation:

$$
\eta_{w} \%=\frac{v-v^{\prime}}{v} \times 100,
$$

where $v \& v^{\prime}$ are the corrosion rate of the metal specimen in the absence and presence of the inhibitor, respectively.

2.4. Electrochemical Corrosion Studies. Three-electrode system was used for polarization studies in which saturated calomel electrode (SCE) acted as reference electrode. Platinum and metal specimen (both having $1 \mathrm{~cm}^{2}$ area) acted as counter and working electrodes, respectively. The working electrode was allowed to contact with the aggressive solution to attain steady-state open-circuit potential (OCP). Each metal specimen was immersed in the aggressive medium for a period of $30 \mathrm{~min}$ prior to the experiment at $29^{\circ} \mathrm{C}$. Polarization studies were carried out in the potential range +250 to $-250 \mathrm{mV}$ with a sweep rate of $1 \mathrm{mV} / \mathrm{s}$ [23-26]. The inhibition efficiencies were calculated from the corrosion current densities using the following equation:

$$
\eta_{\text {pol }} \%=\frac{I_{\text {corr }}-I_{\text {corr }}^{\prime}}{I_{\text {corr }}} \times 100 .
$$

Electrochemical noise (ECN) experiments were performed in a three-electrode cell assembly, which consisted of two carbon steel electrodes $\left(1 \mathrm{~cm}^{2}\right)$ and SCE. All ECN analyses were conducted for a period of $1200 \mathrm{~s}$ [27, 28]. Ivium Compactstate electrochemical system controlled by iviumsoft software was employed for the electrochemical investigations.

2.5. Surface Morphological Studies. SEM analyses were conducted using Hitachi SU6600 model scanning electron microscope. Analysis of surface film deposited on CS was done by IR spectroscopy.

\section{Results and Discussion}

3.1. Structure of Molecules. The structures of molecules were confirmed by $\mathrm{CHN}$ and spectroscopic techniques. The results are summarized as follows. P2APH: $\mathrm{CHN}$, found: (calc.), C\%; 72.69 (73.09), H\%; 4.98 (5.58), N\%; 21.08 (21.32). Mass spectrum; $\mathrm{M}+$ peak $\mathrm{m} / z=196.75$ (base peak) $\left(\left[\mathrm{C}_{12} \mathrm{H}_{11} \mathrm{~N}_{3}\right]^{+}\right),{ }^{1} \mathrm{Hnmr} ; 8.17 \delta(\mathrm{s})(\mathrm{CH}=\mathrm{N}), 12.08(\mathrm{~s})$ (NH), ${ }^{13} \mathrm{Cnmr}$; 148.97 ppm (C-2 pyr), 143.35 ppm (C-1 ph), $144.41 \mathrm{ppm}(\mathrm{CH}=\mathrm{N})$.

RP2APH: CHN, found: (calc.), C\%; 71.69 (72.36), H\%; 6.66 (6.53), N\%; 20.87 (21.11). Mass spectrum; M+ peak $m / z=198.84$ (base peak) $\left(\left[\mathrm{C}_{12} \mathrm{H}_{13} \mathrm{~N}_{3}\right]^{+}\right),{ }^{1} \mathrm{Hnmr}$; 6.8(t) $\left(\mathrm{CH}_{2}\right), 8.5 \delta(\mathrm{d})(\mathrm{NH}-1), 10.67 \delta(\mathrm{d})(\mathrm{NH}-2),{ }^{13} \mathrm{Cnmr}$; $111.39 \mathrm{ppm}\left(\mathrm{CH}_{2}\right), 153.78 \mathrm{ppm}$ (C-2 pyr), $148.18 \mathrm{ppm}(\mathrm{C}-1$ $\mathrm{ph})$. The structures and optimized geometries of molecules $\mathrm{P} 2 \mathrm{APH}$ and RP2APH are given in Figure 1.

3.2. Gravimetric Corrosion Inhibition Studies. The corrosion inhibition efficiencies of two molecules for $24 \mathrm{~h}$ at $\left(29 \pm 0.1^{\circ} \mathrm{C}\right)$ are listed in Table 1 . Both molecules displayed very high inhibition efficiency on CS surface. For a period of $24 \mathrm{~h}$, the P2APH molecule showed little bit higher inhibition efficiency than its reduced form RP2APH at all concentrations. This can be attributed to the presence of strongly coordinating azomethine linkage in $\mathrm{P} 2 \mathrm{APH}$ and the complete planar geometry of the molecule. Figure 2 represents the variation of corrosion inhibition efficiency with time for the molecules at $1.0 \mathrm{mM}$. The plot reveals that decrease of $\eta_{w} \%$ for $\mathrm{P} 2 \mathrm{APH}$ was very much steeper than that of RP2APH as the days went on. This may be due to the slow hydrolysis of P2APH molecules in acidic medium. The azomethine linkage $(\mathrm{C}=\mathrm{N})$ present in the molecule is susceptible to hydrolysis [11]. The 


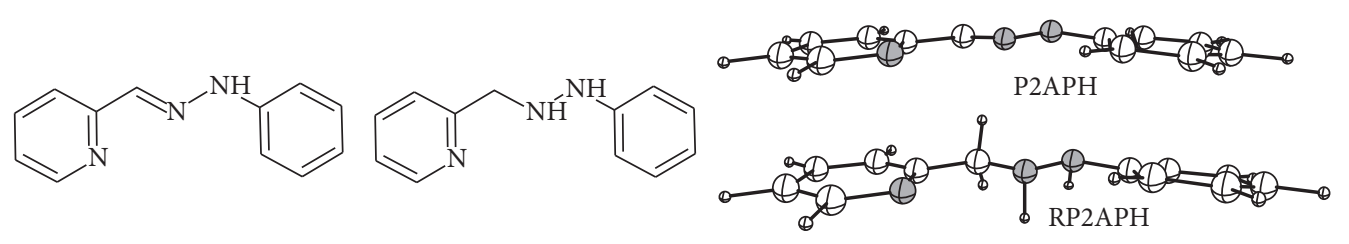

FIgURE 1: Structure of P2APH and RP2APH and their optimized geometries.

TABLE 1: Gravimetric corrosion inhibition efficiencies $\left(\eta_{w} \%\right)$ of $\mathrm{P} 2 \mathrm{APH}$ and RP2APH on CS in $1 \mathrm{M} \mathrm{HCl}$ for $24 \mathrm{~h}$ at $29 \pm 0.2^{\circ} \mathrm{C}$.

\begin{tabular}{lcc}
\hline$C(\mathrm{mM})$ & $\mathrm{P} 2 \mathrm{APH}$ & $\mathrm{RP} 2 \mathrm{APH}$ \\
\hline 0.2 & 92.14 & 91.64 \\
0.4 & 92.98 & 91.91 \\
0.6 & 94.42 & 92.57 \\
0.8 & 94.82 & 93.80 \\
1.0 & 95.50 & 95.40 \\
\hline
\end{tabular}

reduced form of this molecule (RP2APH) is free from the azomethine linkage and is not vulnerable to hydrolysis and showed higher inhibition efficiency for days. The stability of the inhibitor in the aggressive medium is very important if it is to be recommended for a long time use. From the results of gravimetric corrosion studies one can reach into the conclusion that RP2APH molecule acts as very good corrosion inhibitor for a long time.

To get a more insight into the mechanism of corrosion, adsorption isotherms were plotted. Among the various isotherm models tried, the most suitable one was selected with the help of correlation coefficient. The most fit isotherm model for P2APH and RP2APH on $\mathrm{CS}$ in $1 \mathrm{M} \mathrm{HCl}$ was Langmuir adsorption isotherm equation (4). Isotherm plots having correlation coefficients close to one are given in Figure 3.

$$
\frac{C}{\theta}=\frac{1}{K_{\mathrm{ads}}}+C
$$

where $C$ is the concentration of the inhibitor, $\theta$ is the fractional surface coverage, and $K_{\text {ads }}$ is the adsorption equilibrium constant [1]. Standard free energy of adsorption $\left(\Delta G_{\mathrm{ads}}^{0}\right)$ is related to equilibrium constant of adsorption $\left(K_{\mathrm{ads}}\right)$ by the following equation:

$$
\Delta G_{\mathrm{ads}}^{0}=-R T \ln \left(55.5 K_{\mathrm{ads}}\right),
$$

where 55.5 is the molar concentration of water, $R$ is the universal gas constant, and $T$ is the temperature in Kelvin. Both molecules exhibited free energies of adsorption approximately $38.0 \mathrm{~kJ} / \mathrm{mol}$, which established that both the molecules interact with the metal surface by strong chemical forces [29].

3.3. Polarization Studies. To get an idea about the electrokinetic reactions and the involvement of molecules in the process polarization studies have been performed. Table 2 provides the Tafel polarization parameters of CS in the presence and absence of the inhibiting molecules. Figures 4(a) and 4(b)

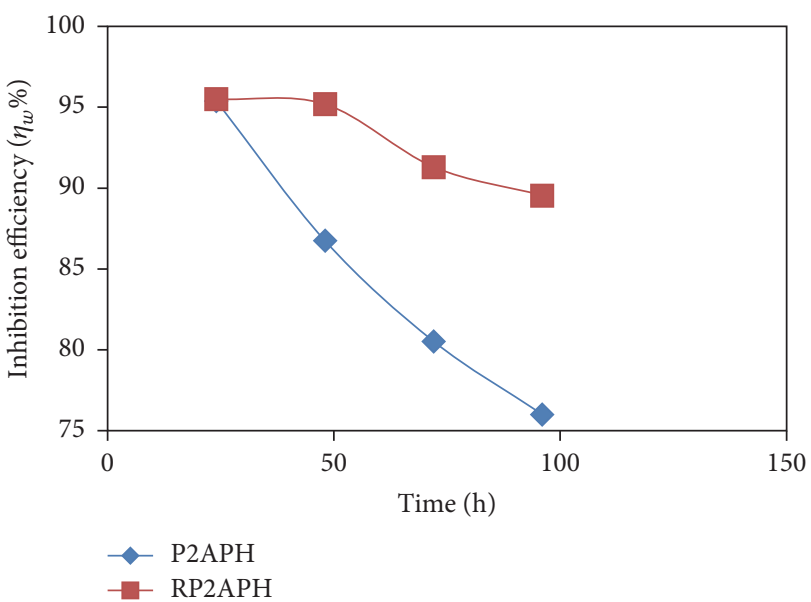

FIgURE 2: Variation of corrosion inhibition efficiencies $\left(\eta_{w} \%\right)$ of $1.0 \mathrm{mM}$ P2APH and RP2APH with time on CS in $1 \mathrm{M} \mathrm{HCl}$.

show the Tafel polarization curves for metal specimens in $1 \mathrm{M}$ $\mathrm{HCl}$ with and without P2APH and RP2APH. The corrosion current density of the metal specimens markedly decreased with the concentration of inhibitors. A significant reduction of the active surface area of the metal specimen exposed to the corrosive medium occurs due to the increase of the thickness of the adsorbed layer with concentration [14]. The notable rise in $\eta_{\text {pol\% }}$ was observed by these inhibitors with concentration. At $1.0 \mathrm{mM}$ concentration, P2APH displayed $92.3 \%$ inhibition efficiency. Since the cathodic slopes of Tafel lines (Figure 4) were deviated more than anodic slopes, one can assume that these two molecules delay the metal corrosion by inhibiting the cathodic process of corrosion more. In other words, the hydrogen evolution process was considerably hindered by both molecules compared to the oxidation of Fe into $\mathrm{Fe}^{2+}$.

3.4. Electrochemical Noise Studies. Electrochemical noise experiments were performed with identical CS electrodes and reference electrode (SCE) immersed in the test solution (1 M $\mathrm{HCl}$ ) in the presence and absence of P2APH and RP2APH for a period of $1200 \mathrm{~s}$ at $29 \pm 0.2^{\circ} \mathrm{C}$. Figure 5 represents the current noise for blank metal specimen and metal treated with acid in the presence of $1.0 \mathrm{mM}$ P2APH and RP2APH. From the noise data it is understandable that the mean values of the current noise follow the order blank > RP2APH > P2APH, which reveals that the protective power of the molecules is in the order P2APH > RP2APH. The ratio of standard deviation of potential noise to the standard deviation of current noise gave the noise resistance $R_{n}$ [30]. The noise resistance for 
TABLE 2: Potentiodynamic polarization parameters of CS in the presence and absence of P2APH and RP2APH in $1 \mathrm{M} \mathrm{HCl}$ at $29 \pm 0.2^{\circ} \mathrm{C}$ for immersion period of $30 \mathrm{~min}$.

\begin{tabular}{|c|c|c|c|c|c|c|c|c|c|c|}
\hline \multirow[b]{2}{*}{$\begin{array}{l}C \\
(\mathrm{mM})\end{array}$} & \multicolumn{5}{|c|}{ P2APH } & \multicolumn{5}{|c|}{$\mathrm{RP} 2 \mathrm{APH}$} \\
\hline & $\begin{array}{c}-E_{\text {corr }} \\
(\mathrm{mV} / \mathrm{SCE})\end{array}$ & $\begin{array}{c}I_{\text {corr }} \\
\left(\mu \mathrm{A} / \mathrm{cm}^{2}\right)\end{array}$ & $\begin{array}{c}-b_{c} \\
(\mathrm{mV} / \mathrm{dec})\end{array}$ & $\begin{array}{c}b_{a} \\
(\mathrm{mV} / \mathrm{dec})\end{array}$ & $\eta_{\mathrm{pol} \%}$ & $\begin{array}{c}-E_{\text {corr }} \\
(\mathrm{mV} / \mathrm{SCE})\end{array}$ & $\begin{array}{c}I_{\text {corr }} \\
\left(\mu \mathrm{A} / \mathrm{cm}^{2}\right)\end{array}$ & $\begin{array}{c}-b_{c} \\
(\mathrm{mV} / \mathrm{dec})\end{array}$ & $\begin{array}{c}b_{a} \\
(\mathrm{mV} / \mathrm{dec})\end{array}$ & $\eta_{\mathrm{pol} \%}$ \\
\hline 0 & 531 & 639.31 & 102 & 152 & - & 531 & 639.31 & 102 & 152 & \\
\hline 0.2 & 511 & 383.20 & 110 & 137 & 40.03 & 433 & 375.61 & 126 & 161 & 41.22 \\
\hline 0.4 & 497 & 219.93 & 85 & 123 & 66.68 & 517 & 249.71 & 122 & 175 & 60.92 \\
\hline 0.6 & 488 & 108.08 & 67 & 126 & 83.08 & 511 & 206.93 & 94 & 162 & 67.62 \\
\hline 0.8 & 501 & 55.67 & 52 & 126 & 91.23 & 509 & 105.76 & 119 & 168 & 83.45 \\
\hline 1.0 & 484 & 49.40 & 112 & 136 & 92.27 & 512 & 77.55 & 146 & 167 & 87.86 \\
\hline
\end{tabular}

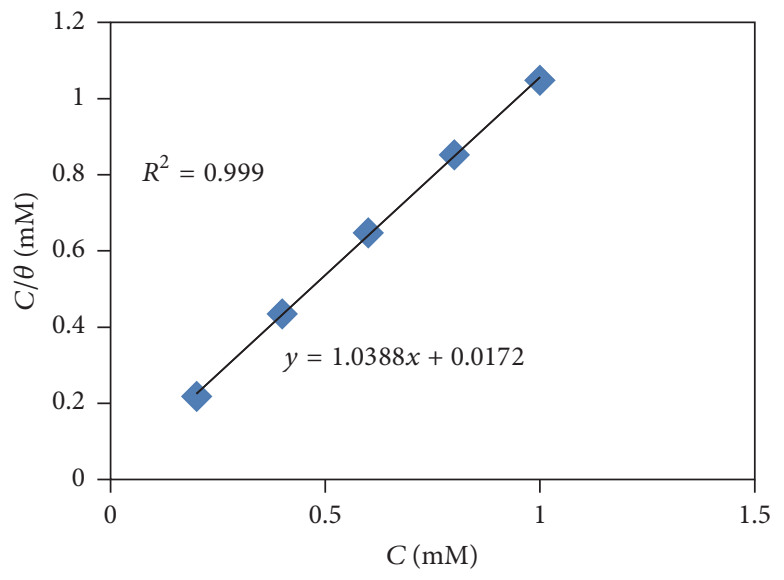

(a)

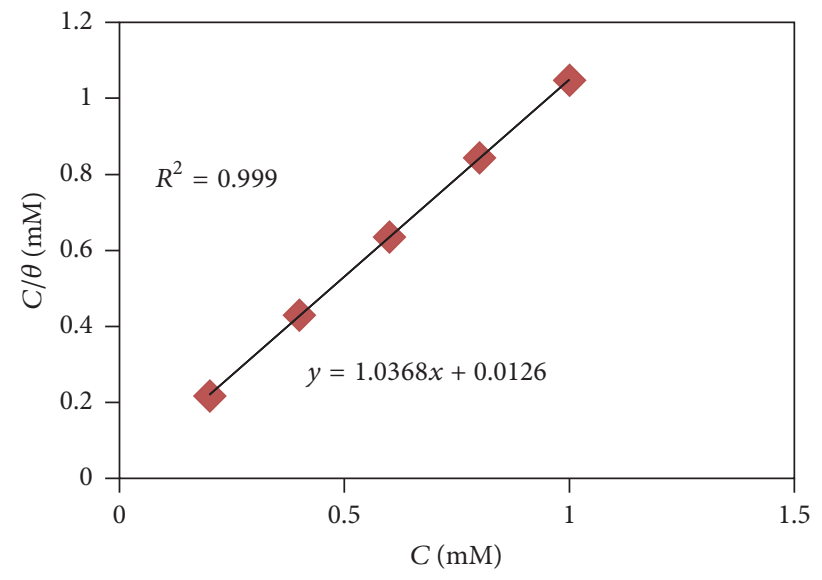

(b)

FIGURE 3: Langmuir adsorption isotherm for (a) P2APH and (b) RP2APH on CS in $1 \mathrm{M} \mathrm{HCl}$ for $24 \mathrm{~h}$.

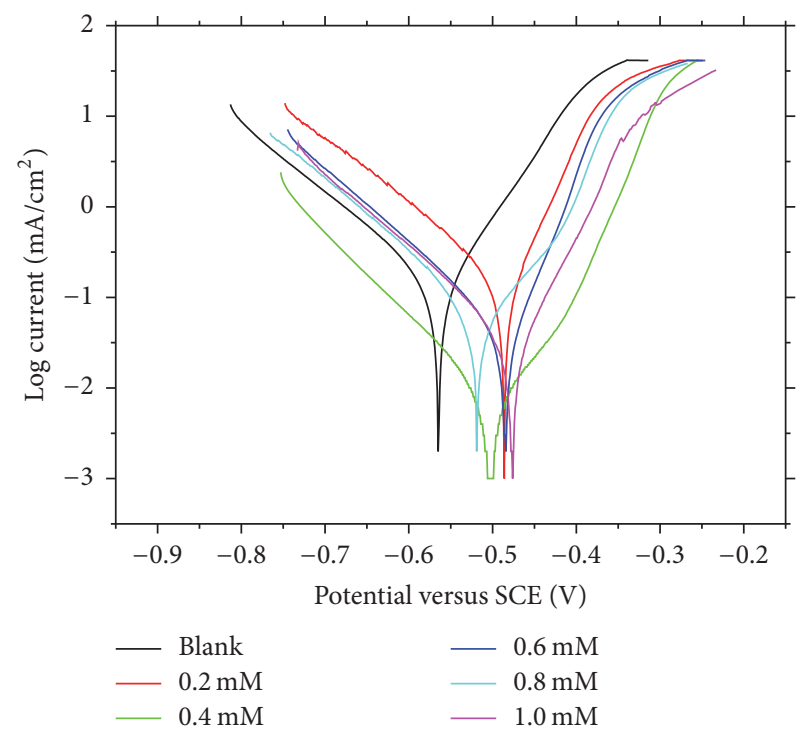

(a)

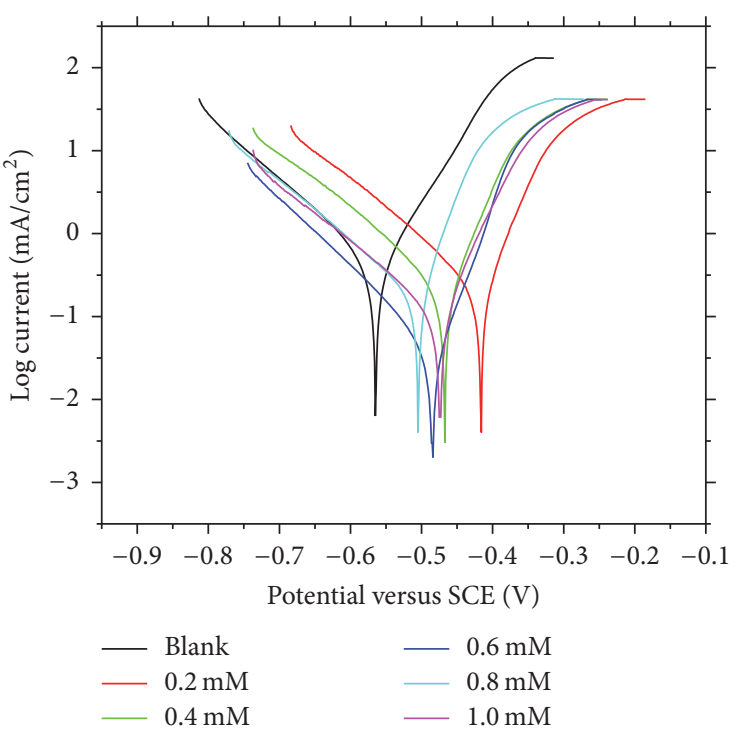

(b)

FIgURE 4: Tafel lines for CS in the absence and presence of (a) P2APH and (b) RP2APH in $1 \mathrm{M} \mathrm{HCl}$ at $29 \pm 0.2^{\circ} \mathrm{C}$. 


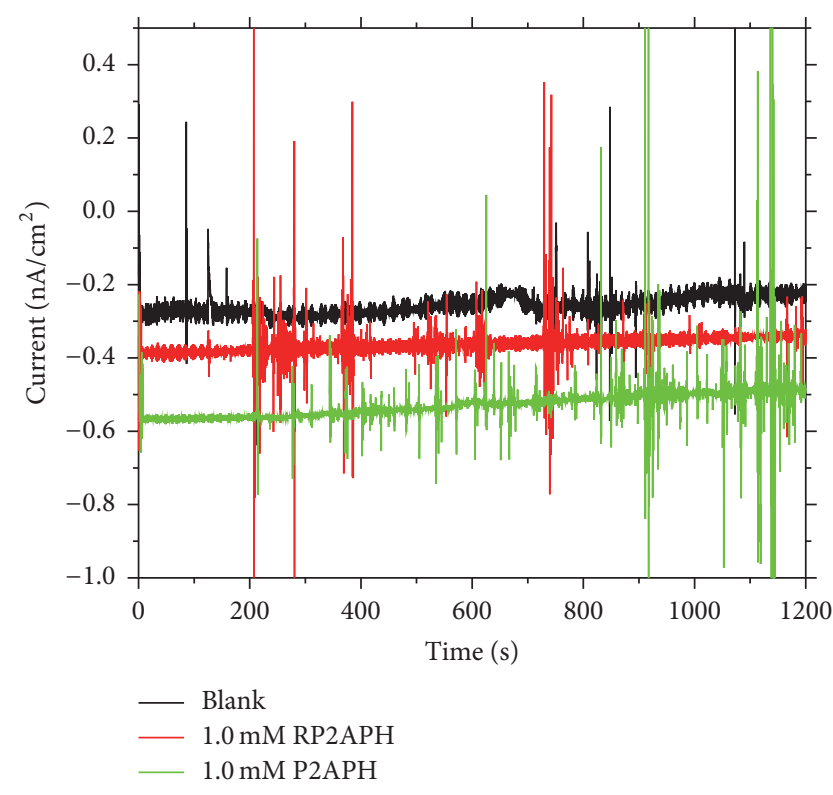

FIGURE 5: Current noise for CS in the absence and presence of $\mathrm{P} 2 \mathrm{APH}$ and $\mathrm{RP} 2 \mathrm{APH}(1.0 \mathrm{mM})$ in $1 \mathrm{M} \mathrm{HCl} 29 \pm 0.2^{\circ} \mathrm{C}$.

the blank metal specimen was 2.8 , which was increased appreciably by the addition of inhibitors. CS treated with P2APH and RP2APH displayed noise resistances 4.22 and 3.92 , respectively, which obviously reflects the involvement of molecules in the metal dissolution process.

The frequency domain analysis of noise data gave the Power spectral density (PSD) of various systems (Figure 6). The advantage of PSD is that it is independent of time and the signal statistics do not alter with time [31-33]. Fast Fourier Transformation (FFT) was adopted to convert time dependent noise data into PSD plots using ivium software. The frequency response of the noise signals can be monitored with the help of PDS plots. To improve the spectral resolution, Burg introduced maximum entropy method (MEM) for short time records [34]. Mathematically this method makes some assumptions about unmeasured data which are consistent with the existing data [35]. The red lines shown in the FFT spectrum of various CS specimens depicts MEM curves.

Current and potential noise for the blank specimen were comparatively higher than the specimens treated with inhibiting molecules. The magnitude of noise was significantly lowered with the frequency. Higher amplitude of potential noise signal is an indication of appreciable localized metallic corrosion [36]. On analyzing the PSD plots and MEM curves, it is clear that the magnitude of potential noise values is very much higher for blank metal specimen than the specimens immersed in acid in the presence of $\mathrm{P} 2 \mathrm{APH}$ and RP2APH (1.0 mM). This is the indication of the considerable localized corrosion on CS surface in the absence of inhibitors. At all frequencies potential noise and current noise of CS treated with P2APH are lower than those of specimen treated with RP2APH, suggesting that the former molecule inhibits well the dissolution of CS in $1 \mathrm{M} \mathrm{HCl}$.
The slope of the PSD plot is important parameter which depicts the response of the inhibiting molecules on the metal surface. A considerable change in the magnitude of slope of a PSD plot is a measure of the vulnerability for the metal dissolution [37]. Though the slopes of the $\mathrm{PSD}_{v}$ curves almost remain unchanged for CS treated with $1.0 \mathrm{mM}$ P2APH and $\mathrm{RP} 2 \mathrm{APH}$, significant change in the slopes of $\mathrm{PSD}_{i}$ plots was noticed. Slopes of $\mathrm{PSD}_{i}$ spectral curves of CS specimen treated with $1.0 \mathrm{mM}$ inhibitor molecules roughly changed to zero from -0.19 . This result establishes that carbon steel in the presence of $\mathrm{P} 2 \mathrm{APH}$ and $\mathrm{RP} 2 \mathrm{APH}$ is less vulnerable to corrosion in $1 \mathrm{M} \mathrm{HCl}$.

3.5. IR Spectral Studies. The surface film deposited on the CS specimen treated with $1.0 \mathrm{mM}$ inhibitor in the aggressive medium for $24 \mathrm{~h}$ was removed mechanically and analyzed using IR spectroscopy. Figures 7(a) and 7(b) denote the overlay IR spectra of the P2APH and RP2APH and their surface film spectra on CS surface, respectively. The phenylhydrazone P2APH displayed a peak at $3330 \mathrm{~cm}^{-1}$ which was due to the stretching vibration of N-H group. This peak in the surface film spectrum shifted to higher frequency $\left(3420 \mathrm{~cm}^{-1}\right)$ with very strong absorption. When we consider the structure of $\mathrm{P} 2 \mathrm{APH}$, the ample chance for the intramolecular hydrogen bonding between the heterocyclic nitrogen atom and $\mathrm{N}-\mathrm{H}$ group is very obvious. The enhancement of N-H stretching frequency in the surface film spectrum may be due to the rupturing of hydrogen bond during the adsorption of molecule on CS surface through the $\mathrm{N}$-atom of the pyridine ring which will lead to the free vibration of $\mathrm{N}-\mathrm{H}$ bond. The $\mathrm{CH}=\mathrm{N}$ stretching frequency appearing at $1600 \mathrm{~cm}^{-1}$ in the IR spectrum of P2APH changed to $1620 \mathrm{~cm}^{-1}$ in the spectrum of surface film. This is due to the interaction of this group with the surface metal atoms. The C-N(pyr) stretching vibration of $\mathrm{P} 2 \mathrm{APH}$ was also shifted from $1540 \mathrm{~cm}^{-1}$ to $1520 \mathrm{~cm}^{-1}$ in surface film spectrum which is a clear indication of the interaction of the compound with metal atoms through pyridine nitrogen. Strong absorption below $900 \mathrm{~cm}^{-1}$ in the spectrum of surface film can be attributed to the formation of metal-nitrogen and metal-carbon bonds. Due to the lack of complete coplanarity of RP2APH, it is difficult to propose intramolecular hydrogen bonding. The N-H stretching frequency appearing at $3400 \mathrm{~cm}^{-1}$ in the spectrum of RP2APH is not appreciably altered in the spectrum of surface film. The peak observed at $1580 \mathrm{~cm}^{-1}$ was changed to $1600 \mathrm{~cm}^{-1}$ in the IR spectrum of surface film, which can be attributed to the interaction of pyridine nitrogen with Fe atoms. Below $1000 \mathrm{~cm}^{-1}$, the spectrum of surface film of RP2APH exhibited very intense IR absorption indicating the formation of strong $\mathrm{Fe}-\mathrm{N}$ and $\mathrm{Fe}-\mathrm{C}$ bonds.

3.6. SEM Studies. Surface morphology of the metal surfaces was evaluated with the aid of SEM. All micrographs were recorded at a magnification of 200x. Figures 8(a)$8(\mathrm{~d})$, respectively, show the magnified surface images of bare metal, metal immersed in acid, and metal treated with acid in the presence of P2APH and RP2APH $(1.0 \mathrm{mM})$ for 


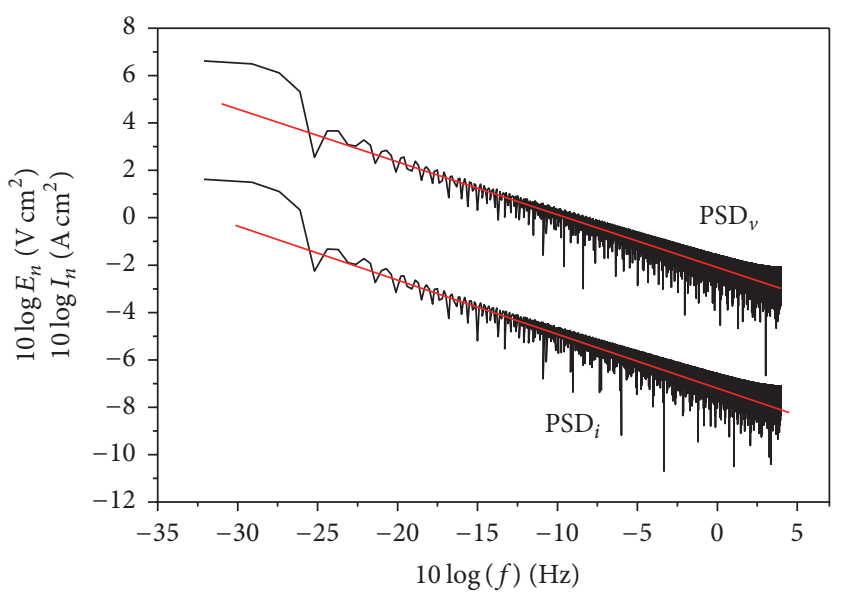

(a)

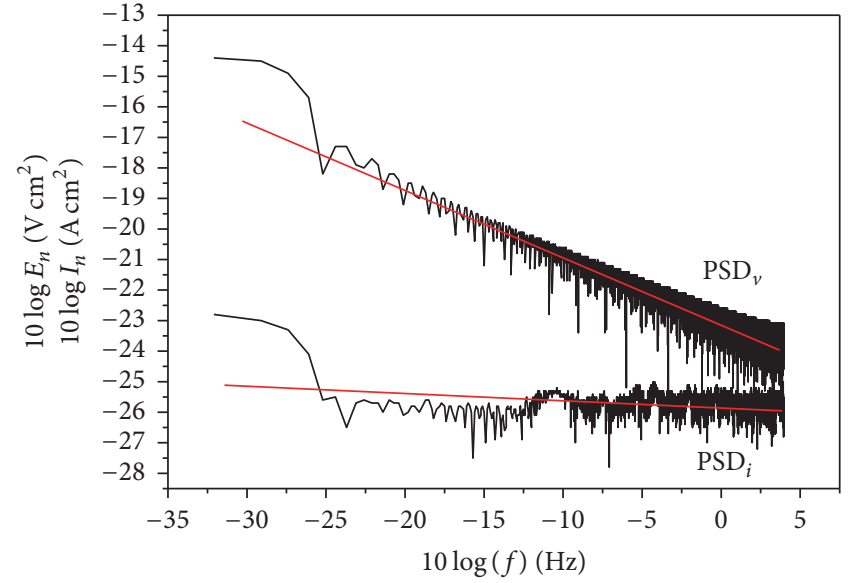

(b)

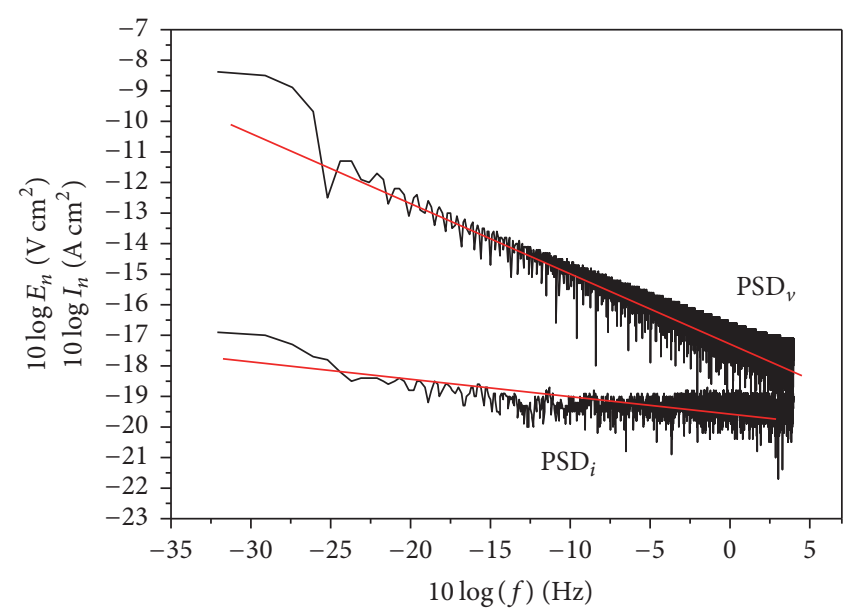

(c)

FIGURE 6: Power spectral density (current and voltage) of CS (a) and blank (b) in presence of P2APH and (c) RP2APH (1.0 mM) in $1 \mathrm{M} \mathrm{HCl}$.

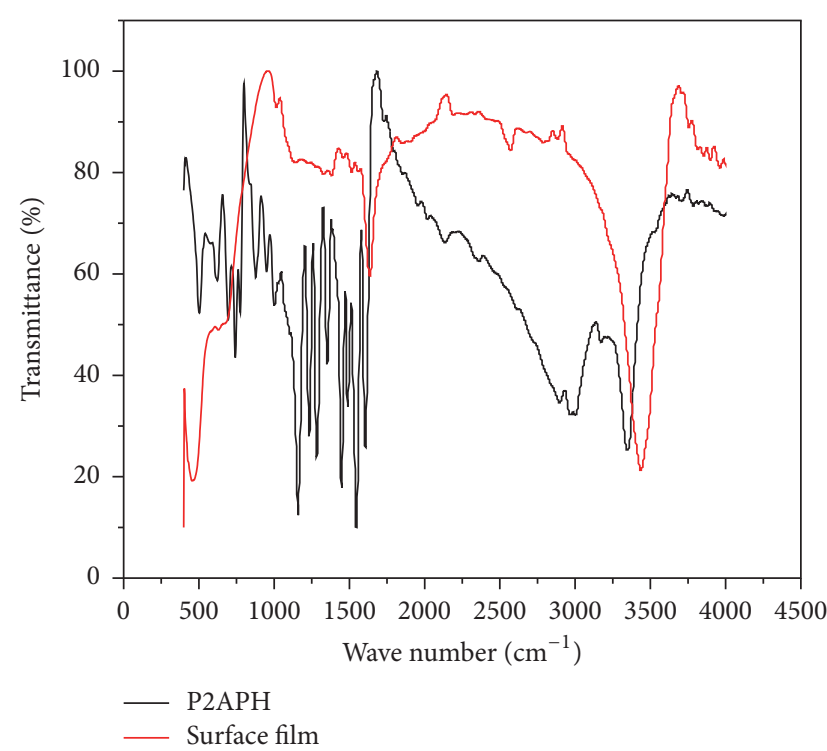

(a)

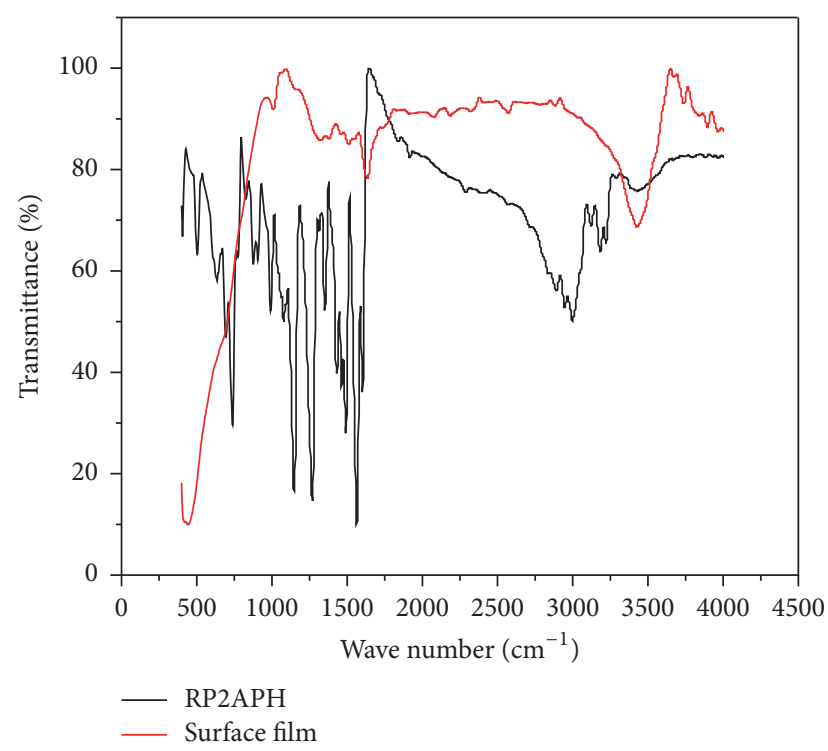

(b)

FIGURE 7: IR spectrum of (a) P2APH and surface film on CS; (b) RP2APH and surface film on CS. 


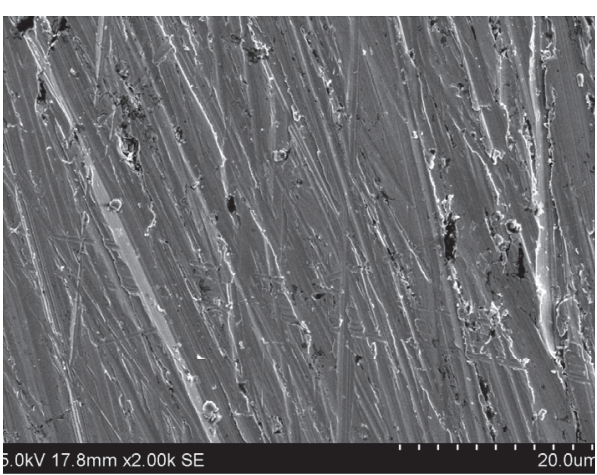

(a)

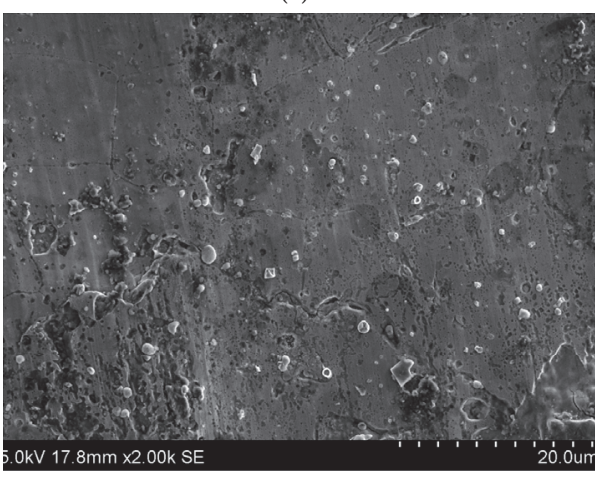

(c)

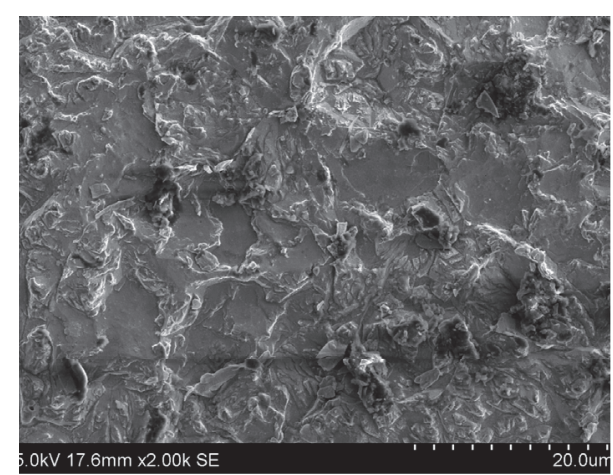

(b)

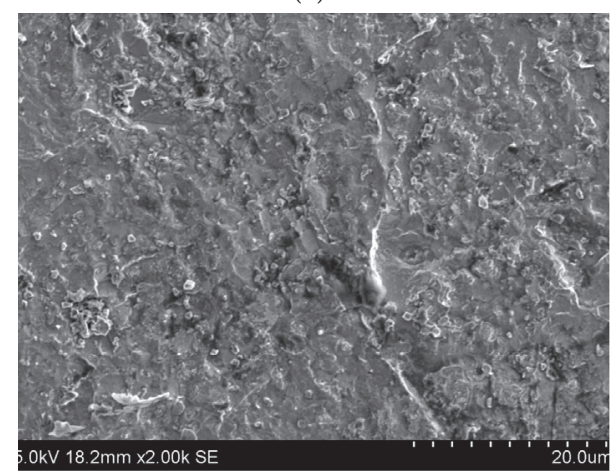

(d)

FIGURE 8: SEM images of (a) bare metal; (b) CS treated with $1.0 \mathrm{M} \mathrm{HCl}$; (c) with P2APH (1.0 mM); (d) with RP2APH (1.0 mM) for $24 \mathrm{~h}$.

$24 \mathrm{~h}$. The textures of all surface images showed considerable differences. The pits and cracks appearing in the SEM image of the bare metal specimen were due to the polishing effects. The micrograph of blank specimen appeared to be very rough due to severe corrosion. Comparatively smoother images were displayed by metal specimens immersed in $\mathrm{HCl}$ in the presence of P2APH (1.0 mM) and RP2APH (1.0 mM). This can be attributed to the prevention of CS acid corrosion in acid by the adsorption of molecules.

3.7. Quantum Chemical Calculations. The corrosion inhibition response of organic molecules can be correlated with the energy of frontier molecular orbitals. The donor-acceptor interactions (HSAB concept) between the filled molecular orbitals of the inhibitor molecules and the vacant d-orbitals of $\mathrm{Fe}$ atoms on the surface are very important in the prevention of metal dissolution. High value of $E_{\mathrm{HOMO}}$ and the lowest value of $E_{\mathrm{LUMO}}-E_{\mathrm{HOMO}}(\Delta E)$ are the important quantum chemical parameters which facilitate the strong binding of the molecules on the metal surface $[34,38]$. Optimization of geometry of molecules and quantum chemical calculations were performed by DFT method using GAMMES software. A combination of Beck's three-parameter exchange functional and Lee-Yang-Parr nonlocal correlation functional (B3LYP) was employed in DFT calculations [34]. Estimated quantum mechanical parameters like $E_{\mathrm{HOMO}}, E_{\mathrm{LUMO}}$, and $\Delta E$ for $\mathrm{P} 2 \mathrm{APH}$ and RP2APH are provided in Table 3. The HOMO and LUMO of the molecules are $\mathrm{P} 2 \mathrm{APH}$ and RP2APH represented in Figure 9. Approximate HSAB parameters like electronegativity $(\chi)$ and chemical hardness $(\eta)$ of the molecules were evaluated by the following equations [39] and are also reported in Table 3:

$$
\begin{aligned}
& \chi \approx-\frac{1}{2}\left(E_{\mathrm{HOMO}}+E_{\mathrm{LUMO}}\right), \\
& \eta \approx \frac{1}{2}\left(E_{\mathrm{HOMO}}-E_{\mathrm{LUMO}}\right) .
\end{aligned}
$$

The $E_{\text {Homo }}$ values of the two molecules were almost the same, but the energy separation between HOMO and LUMO was considerably lower for $\mathrm{P} 2 \mathrm{APH}$ than RP2APH, which indicate that $\mathrm{P} 2 \mathrm{APH}$ is a finer inhibitor than RP2APH. The energy required to render electrons from $\mathrm{HOMO}$ of $\mathrm{P} 2 \mathrm{APH}$ to the vacant d-orbitals of $\mathrm{Fe}$ is low compared to that of RP2APH. Lowest value of $E_{\mathrm{LUMO}}$ is an indication of the higher probability of the molecule to accept electrons from the metal surface. On comparing the $E_{\text {LUMO }}$ values of the two molecules, it is obvious that P2APH molecule possesses very low value than RP2APH. This originates a strong backdonation of electrons from the filled orbital of Fe to the unoccupied molecular orbital of P2APH. Quantum chemical parameters provide a room for the calculation of number of electrons transferred $(\Delta N)$ from donor to acceptor molecules. As an approximation, the chemical hardness of Fe bulk metal is assumed as zero and the approximate electronegativity of bulk Fe is taken as $7 \mathrm{eV}$ [39]. Equation (7) gives the approximate quantity of electrons transferred from the inhibitor molecule to the Fe atoms.

$$
\Delta N=\frac{\chi_{\mathrm{Fe}-} \chi_{\mathrm{inhib}}}{2\left(\eta_{\mathrm{Fe}+} \eta_{\text {inhib }}\right)} .
$$


TABLE 3: Quantum chemical parameters of P2APH and RP2APH.

\begin{tabular}{lccccrc}
\hline Molecule & $E_{\text {HOMO }}(\mathrm{eV})$ & $E_{\text {LUMO }}(\mathrm{eV})$ & $\Delta E(\mathrm{eV})$ & $\chi$ & \multicolumn{1}{c}{$\eta$} \\
\hline P2APH & -3.4640 & 0.7429 & 4.2069 & 1.36055 & 2.10345 & 1.340524 \\
RP2APH & -3.4613 & 1.4803 & 4.941 & 0.9905 & 2.4708 & 1.216104 \\
\hline
\end{tabular}

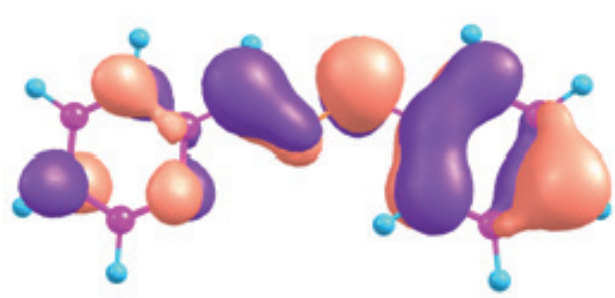

P2APH (HOMO)

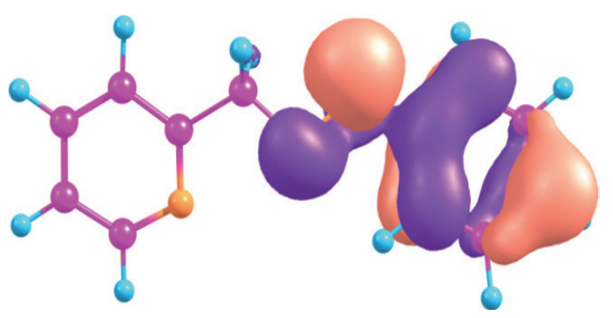

RP2APH (HOMO)

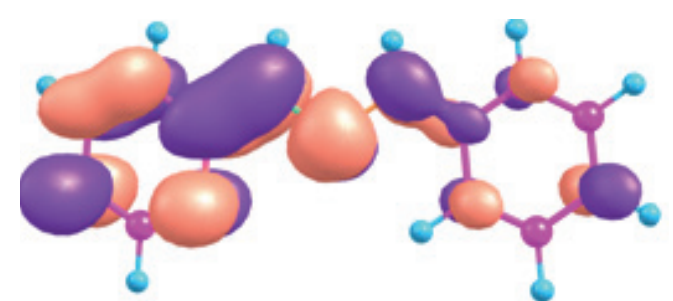

P2APH (LUMO)

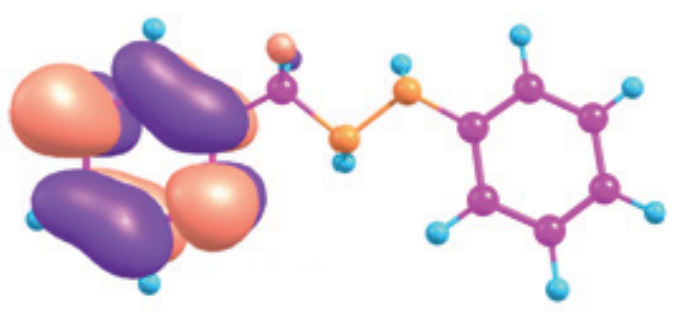

RP2APH (LUMO)

FIGURE 9: HOMO and LUMO of P2APH and RP2APH.

The number of electrons transferred from the inhibitor to the acceptor atom is higher for P2APH than RP2APH, which suggests that $\mathrm{P} 2 \mathrm{APH}$ can make a strong coordinate type interaction with the metal atoms.

Perturbation of electron cloud occurs in molecules during chemical reaction. Chemical hardness of a molecule is a measure of resistance against the polarization of electron cloud. Soft molecules generally have low value of chemical hardness, low HOMO-LUMO energy gap, and high polarizability [40]. They are also associated with high chemical reactivity. If we consider the interaction of Fe with two organic molecules as soft-soft type, it is evident that P2APH has a great tendency to adsorb on Fe surface and hence prevent the metal dissolution appreciably, since it possesses low value of chemical hardness than RP2APH.

\section{Conclusions}

(1) $\mathrm{P} 2 \mathrm{APH}$ and its reduced form RP2APH were very effective corrosion inhibitors for $\mathrm{CS}$ in $\mathrm{HCl}$ medium.

(2) All corrosion monitoring studies revealed that inhibition efficiency of $\mathrm{P} 2 \mathrm{APH}$ is greater than that of RP2APH at all concentrations, which may be attributed to the presence of azomethine linkage present in $\mathrm{P} 2 \mathrm{APH}$.

(3) Gravimetric corrosion studies showed that the prolonged corrosion inhibition efficiency of molecules follows the order RP2APH > P2APH.

(4) Two molecules obeyed Langmuir adsorption isotherm on CS surface during the inhibition process.
(5) The inhibitors delay the process of corrosion by hindering the cathodic process mainly.

(6) The participation of P2APH and RP2APH in preventing the localized corrosion on $\mathrm{CS}$ in $\mathrm{HCl}$ was verified by electrochemical noise studies.

(7) Quantum chemical studies differentiated the protective power of molecules.

(8) Surface analysis using SEM and IR clearly portrayed the anticorrosive mechanism of inhibitors.

\section{Competing Interests}

The authors declare that they have no competing interests.

\section{Acknowledgments}

Authors are grateful to TEQIP (phase II), Government Engineering College, Thrissur, Kerala, India, for the financial assistance in the form of seed money project.

\section{References}

[1] V. P. Raphael, K. J. Thomas, K. S. Shaju, and A. Paul, “Corrosion inhibition investigations of 3-acetylpyridine semicarbazone on carbon steel in hydrochloric acid medium," Research on Chemical Intermediates, vol. 40, no. 8, pp. 2689-2701, 2014.

[2] S. John, B. Joseph, K. V. Balakrishnan, K. K. Aravindakshan, and A. Joseph, "Electrochemical and quantum chemical 
study of 4-[(E)-[(2,4-dihydroxy phenyl) methylidine] amino]6-methyl-3-sulphanylidine-2,3,4,5-tetra hydro-1,2,4-triazin-5one [DMSTT]," Materials Chemistry and Physics, vol. 123, no. 1, pp. 218-224, 2010.

[3] F. Bentiss, M. Traisnel, L. Gengembre, and M. Lagrenée, "Inhibition of acidic corrosion of mild steel by 3,5-diphenyl-4H1,2,4-triazole," Applied Surface Science, vol. 161, no. 1, pp. 194202, 2000.

[4] A. K. Singh, S. K. Shukla, M. Singh, and M. A. Quraishi, "Inhibitive effect of ceftazidime on corrosion of mild steel in hydrochloric acid solution," Materials Chemistry and Physics, vol. 129, no. 1-2, pp. 68-76, 2011.

[5] S. V. Ramesh and A. V. Adhikari, "N/-[4-(diethylamino)benzylidine]-3-[8-(trifluoromethyl) quinolin-4-yl]thiopropano hydrazide) as an effective inhibitor of mild steel corrosion in acid media," Materials Chemistry and Physics, vol. 115, no. 2-3, pp. 618-627, 2009.

[6] A. Fiala, A. Chibani, A. Darchen, A. Boulkamh, and K. Djebbar, "Investigations of the inhibition of copper corrosion in nitric acid solutions by ketene dithioacetal derivatives," Applied Surface Science, vol. 253, no. 24, pp. 9347-9356, 2007.

[7] A. K. Singh and M. A. Quraishi, "Inhibiting effects of 5substituted isatin-based Mannich bases on the corrosion of mild steel in hydrochloric acid solution," Journal of Applied Electrochemistry, vol. 40, no. 7, pp. 1293-1306, 2010.

[8] N. Khalil, "Quantum chemical approach of corrosion inhibition," Electrochimica Acta, vol. 48, no. 18, pp. 2635-2640, 2003.

[9] J. M. Costa and J. M. Lluch, "The use of quantum mechanics calculations for the study of corrosion inhibitors," Corrosion Science, vol. 24, no. 11-12, pp. 929-933, 1984.

[10] E. E. Oguzie, "Inhibiting effect of crystal violet dye on aluminum corrosion in acidic and alkaline media," Chemical Engineering Communications, vol. 196, no. 5, pp. 591-601, 2009.

[11] A. B. da Silva, E. D’Elia, and J. A. da Cunha Ponciano Gomes, "Carbon steel corrosion inhibition in hydrochloric acid solution using a reduced Schiff base of ethylenediamine," Corrosion Science, vol. 52, no. 3, pp. 788-793, 2010.

[12] H.-L. Wang, H.-B. Fan, and J.-S. Zheng, "Corrosion inhibition of mild steel in hydrochloric acid solution by a mercaptotriazole compound," Materials Chemistry and Physics, vol. 77, no. 3, pp. 655-661, 2003.

[13] S. John and A. Joseph, "Electro analytical, surface morphologi$\mathrm{cal}$ and theoretical studies on the corrosion inhibition behavior of different 1,2,4-triazole precursors on mild steel in $1 \mathrm{M}$ hydrochloric acid," Materials Chemistry and Physics, vol. 133, no. 2-3, pp. 1083-1091, 2012.

[14] A. Pourghasemi Hanza, R. Naderi, E. Kowsari, and M. Sayebani, "Corrosion behavior of mild steel in $\mathrm{H}_{2} \mathrm{SO}_{4}$ solution with 1,4-di [1'-methylene- $3^{\prime}$-methyl imidazolium bromide]-benzene as an ionic liquid," Corrosion Science, vol. 107, pp. 96-106, 2015.

[15] N. O. Obi-Egbedi, I. B. Obot, and M. I. El-Khaiary, "Quantum chemical investigation and statistical analysis of the relationship between corrosion inhibition efficiency and molecular structure of xanthene and its derivatives on mild steel in sulphuric acid," Journal of Molecular Structure, vol. 1002, no. 1-3, pp. 8696, 2011.

[16] K. Babic-Samardzija, C. Lupu, N. Hackerman, and A. R. Barron, "Inhibitive properties, adsorption and surface study of butyn-1ol and pentyn-1-ol alcohols as corrosion inhibitors for iron in HCl," Journal of Materials Chemistry, vol. 15, no. 19, pp. 19081916, 2005.
[17] I. Ahamad, R. Prasad, and M. A. Quraishi, "Thermodynamic, electrochemical and quantum chemical investigation of some Schiff bases as corrosion inhibitors for mild steel in hydrochloric acid solutions," Corrosion Science, vol. 52, no. 3, pp. 933-942, 2010.

[18] E. E. Ebenso, M. M. Kabanda, L. C. Murulana, A. K. Singh, and S. K. Shukla, "Electrochemical and quantum chemical investigation of some azine and thiazine dyes as potential corrosion inhibitors for mild steel in hydrochloric acid solution," Industrial and Engineering Chemistry Research, vol. 51, no. 39, pp. 12940-12958, 2012.

[19] S. Erdemir, "Synthesis of novel chiral Schiff base and amino alcohol derivatives of calix[4]arene and chiral recognition properties," Journal of Molecular Structure, vol. 1007, pp. 235241, 2012.

[20] V. K. Aghera and P. H. Parsania, "A cleaner approach for reduction of some symmetric diimines using $\mathrm{NaBH}_{4}$," Indian Journal of Chemistry-Section B Organic and Medicinal Chemistry, vol. 48, no. 3, pp. 438-442, 2009.

[21] N. Kuriakose, J. T. Kakkassery, V. P. Raphael, and S. K. Shanmughan, "Electrochemical impedance spectroscopy and potentiodynamic polarization analysis on anticorrosive activity of thiophene-2-carbaldehyde derivative in acid medium," Indian Journal of Materials Science, vol. 2014, Article ID 124065, 6 pages, 2014.

[22] ASTM, "Standard recommended practice for the laboratory immersion corrosion testing of metals," AST G-31-72, ASTM, Philadelphia, Pa, USA, 1990.

[23] H. H. Hassan, E. Abdelghani, and M. A. Amin, "Inhibition of mild steel corrosion in hydrochloric acid solution by triazole derivatives. Part I. Polarization and EIS studies," Electrochimica Acta, vol. 52, no. 22, pp. 6359-6366, 2007.

[24] A. Dermaj, N. Hajjaji, S. Joiret et al., "Electrochemical and spectroscopic evidences of corrosion inhibition of bronze by a triazole derivative," Electrochimica Acta, vol. 52, no. 14, pp. 4654-4662, 2007.

[25] H. Ashassi-Sorkhabi, T. A. Aliyev, S. Nasiri, and R. Zareipoor, "Inhibiting effects of some synthesized organic compound on the corrosion of St-3 in $0.1 \mathrm{~N} \mathrm{H}_{2} \mathrm{SO}_{4}$ solution," Electrochimica Acta, vol. 52, no. 16, pp. 5238-5241, 2007.

[26] F. B. Growcock and R. J. Jasinski, "Time-resolved impedance spectroscopy of mild steel in concentrated hydrochloric acid," Journal of the Electrochemical Society, vol. 136, no. 8, pp. 23102314, 1989.

[27] J. A. Edward and M. M. Fitelson, "Notes on maximum-entropy processing (Corresp.)," IEEE Transactions on Information Theory, vol. 19, no. 2, pp. 232-234, 1973, Reprinted as 'Modern Spectrum Analysis' (IEEE), 1978.

[28] G. C. Barker, "Noise connected with electrode processes," Journal of Electroanalytical Chemistry and Interfacial Electrochemistry, vol. 21, no. 1, pp. 127-136, 1969.

[29] S. A. Umoren, "Synergistic inhibition effect of polyethylene glycol-polyvinyl pyrrolidone blends for mild steel corrosion in sulphuric acid medium," Journal of Applied Polymer Science, vol. 119, no. 4, pp. 2072-2084, 2011.

[30] M. G. Mahjani, M. Sabzali, M. Jafarian, and J. Neshati, "An investigation of the effects of inorganic inhibitors on the corrosion rate of aluminum alloy using electrochemical noise measurements and electrochemical impedance spectroscopy," Anti-Corrosion Methods and Materials, vol. 55, no. 4, pp. 208216, 2008. 
[31] R. A. Cottis and C. A. Loto, "Electrochemical noise generation during SCC of a high-strength carbon steel," Corrosion, vol. 46, no. 1, pp. 12-19, 1990.

[32] U. Bertocci, J. Frydman, C. Gabrielli, F. Huet, and M. Keddam, "Analysis of electrochemical noise by power spectral density applied to corrosion studies: Maximum entropy method or fast Fourier transform?" Journal of the Electrochemical Society, vol. 145, no. 8, pp. 2780-2786, 1998.

[33] C. H. Chen, Non-Linear Max. Entropy Spectral Analysis Methods for Signal Recognition, Research Studies Press, 1982.

[34] R. M. Issa, M. K. Awad, and F. M. Atlam, "Quantum chemical studies on the inhibition of corrosion of copper surface by substituted uracils," Applied Surface Science, vol. 255, no. 5, pp. 2433-2441, 2008.

[35] B. P. Markhali, R. Naderi, M. Mahdavian, M. Sayebani, and S. Y. Arman, "Electrochemical impedance spectroscopy and electrochemical noise measurements as tools to evaluate corrosion inhibition of azole compounds on stainless steel in acidic media," Corrosion Science, vol. 75, pp. 269-279, 2013.

[36] D. J. Mills, G. P. Bierwagen, B. Skerry, and D. Tallman, "Investigation of anticorrosive coatings by the electrochemical noise method," Materials Performance, vol. 34, no. 5, pp. 33-38, 1995.

[37] R. A. Cottis, M. A. A. Al-Awadhi, H. Al-Mazeedi, and S. Turgoose, "Measures for the detection of localized corrosion with electrochemical noise," Electrochimica Acta, vol. 46, no. 2425, pp. 3665-3674, 2001.

[38] V. S. Sastri and J. R. Perumareddi, "Molecular orbital theoretical studies of some organic corrosion inhibitors," Corrosion, vol. 53, no. 8, pp. 617-622, 1997.

[39] R. G. Pearson, "Absolute electronegativity and hardness: application to inorganic chemistry," Inorganic Chemistry, vol. 27, no. 4, pp. 734-740, 1988.

[40] S. Xia, M. Qiu, L. Yu, F. Liu, and H. Zhao, "Molecular dynamics and density functional theory study on relationship between structure of imidazoline derivatives and inhibition performance," Corrosion Science, vol. 50, no. 7, pp. 2021-2029, 2008. 

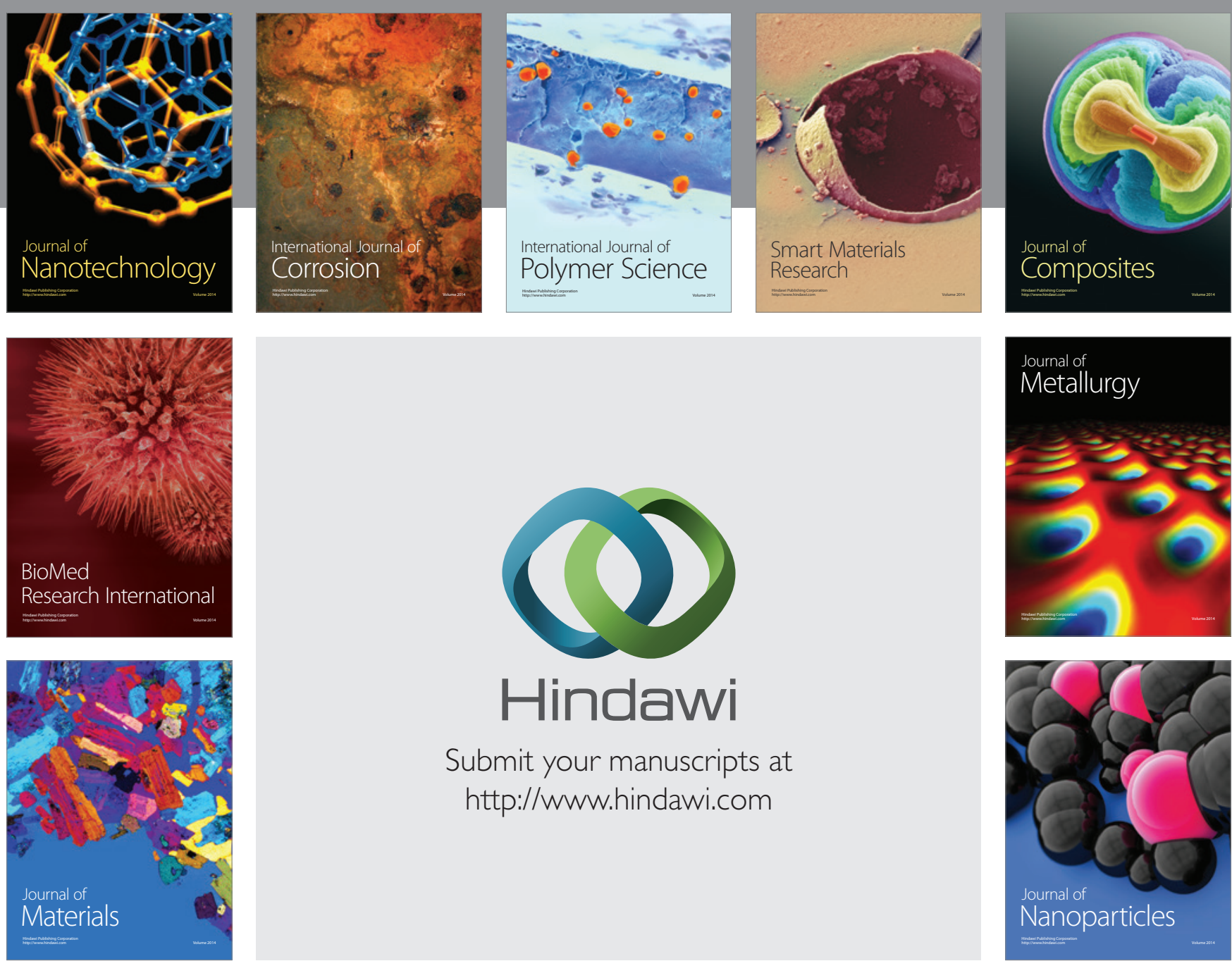

\section{Hindawi}

Submit your manuscripts at

http://www.hindawi.com

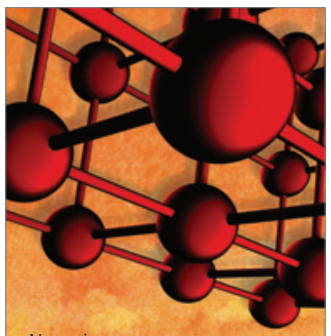

Materials Science and Engineering
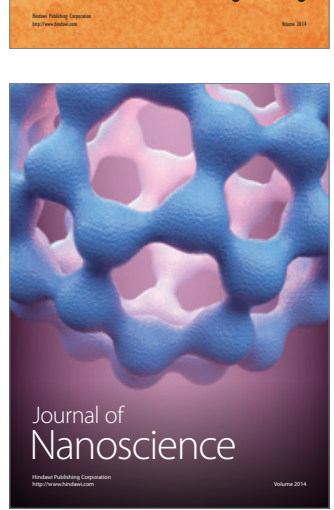
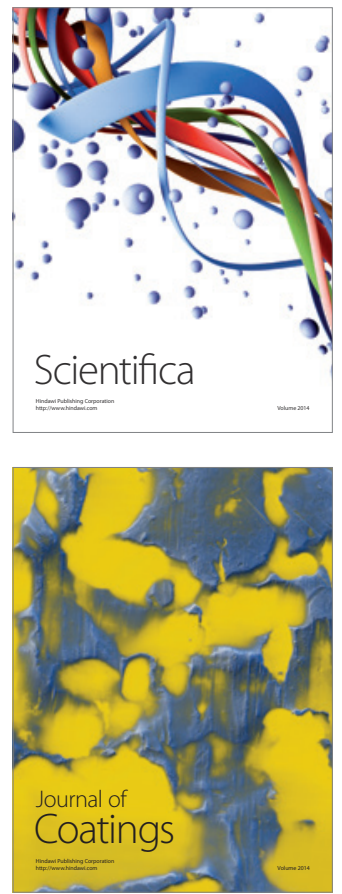
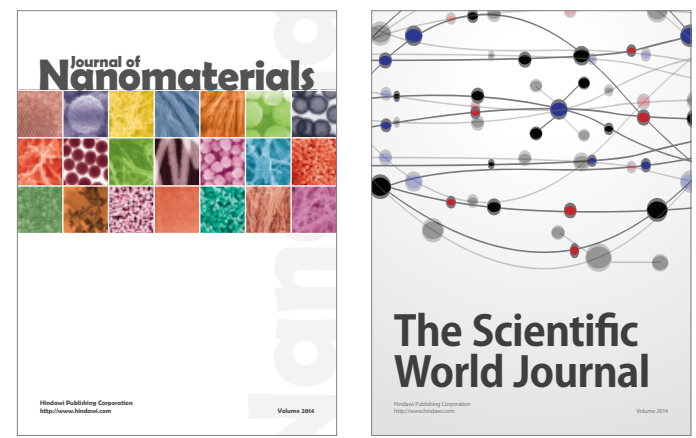

The Scientific World Journal
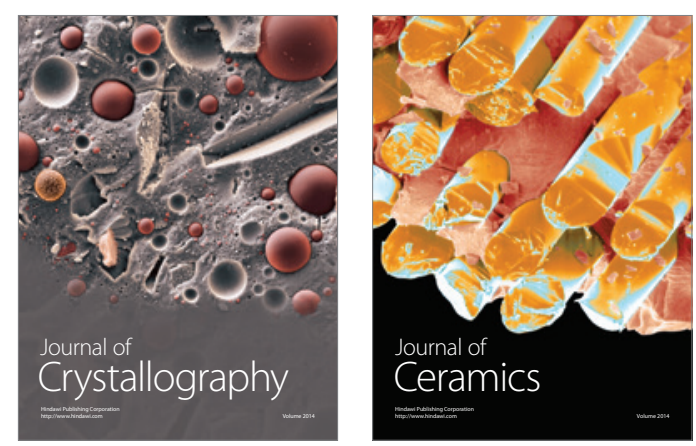
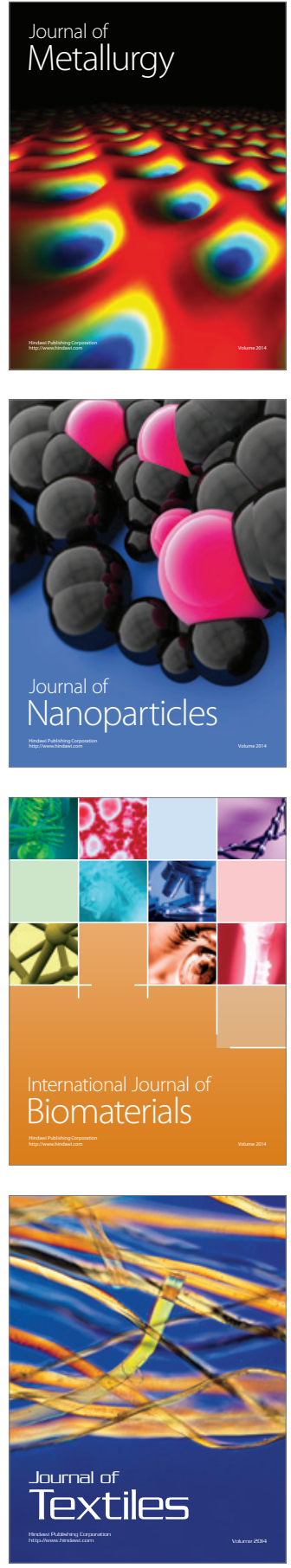